\title{
A Brief Overview of Atom Probe Tomography Research
}

\author{
Baptiste Gault* \\ Department of Microstructure Physics and Alloy Design, Max-Planck-Institut für Eisenforschung GmbH, Düsseldorf 40237, Germany
}

*Correspondence to:

Gault B,

Tel: +49-211-6792-908

Fax: +49-211-6792 333

E-mail: b.gault@mpie.de

Received September 23, 2016

Revised September 26, 2016

Accepted September 26, 2016

\begin{abstract}
Atom probe tomography (APT) has been fast rising in prominence over the past decade as a key tool for nanoscale analytical characterization of a range of materials systems. APT provides three-dimensional mapping of the atom distribution in a small volume of solid material. The technique has evolved, with the incorporation of laser pulsing capabilities, and, combined with progress in specimen preparation, APT is now able to analyse a very range of materials, beyond metals and alloys that used to be its core applications. The present article aims to provide an overview of the technique, providing a brief historical perspective, discussing recent progress leading to the state-of-the-art, some perspectives on its evolution, with targeted examples of applications.
\end{abstract}

Key Words: Atom probe tomography, Field evaporation, Materials characterization, Microscopy, Nanoscale

\section{INTRODUCTION TO ATOM PROBE TOMOGRAPHY}

Atom probe tomography (APT) stems from the field-ion microscope (Müller, 1956) equipped with a time-of-flight mass spectrometer developed by Erwin Müller and his coworkers in 1967 to 1968 (Müller et al., 1968). The technique is henceforth about to celebrate its 50th anniversary. Field ion microscopy makes use of an intense electric field, in the rage of $10^{10} \mathrm{Vm}^{-1}$, to ionize rare gas atoms in the vicinity of the specimen surface. The specimen is shaped as a sharp needle, with a radius of curvature $\mathrm{R}$ in the range of 30 to $200 \mathrm{~nm}$, which enables the generation of electric fields of the appropriate magnitude by biasing the specimen to a few kilovolts (the field is proportional to $\mathrm{V} / \mathrm{R}$ ). The specimen is maintained at low temperature $(20 \sim 80 \mathrm{~K})$ to prevent surface migration and improve the control over the field evaporation process, and the analysis takes place in ultra-high vacuum conditions $\left(\approx 10^{-8} \mathrm{~Pa}\right)$, prior to the introduction of the imaging gas $\left(\approx 10^{-3} \mathrm{~Pa}\right)$. The beams of ions generated near the surface are projected, under the effect of the very intense electric field, onto a screen and the image formed reveals the topography of the specimen surface down to the atomic-level (Müller
\& Bahadur, 1956), allowing to image lattice defects (Beavan et al., 1971; Dagan et al., 2015; Wilde et al., 2000) as well as secondary phases (Faulkner \& Ralph, 1972).

In atom probe experiments, no imaging gas is used, and it is the atoms from the specimen itself that are successively removed in the form of ions. The prevalent theory of field evaporation from metal surfaces involves atoms escaping while their charge is progressively drained back into the surface (Forbes, 1995), and as the singly-charged ion is accelerated away from the surface, it can undergo one or more successive electricfield-induced ionization (Kingham, 1982). In order to achieve time-control of the field evaporation process, high-voltage (Müller et al., 1968) or laser pulses (Bunton et al., 2007; Gault et al., 2006; Kellogg \& Tsong, 1980) are superimposed to a direct current high voltage $\left(\mathrm{V}_{\mathrm{DC}}\right)$ field, as depicted in Fig. 1 , to trigger the departure of the ions. This, in turns, allows for elemental identification of each evaporated ion by timeof-flight mass spectrometry. The emission of the ions takes place during the pulse, and in the case of the voltage-pulsed instrument, and although the pulse is in the nanosecond time range, ions are emitted with a range of energies, that cause a spread of the times-of-flight for ions of a single element, which limit the mass resolving power of the technique.

(a) This is an open-access article distributed under the terms of the Creative Commons Attribution Non-Commercial License (http://creativecommons.org/licenses/by-nc/4.0) which permits unrestricted noncommercial use, distribution, and reproduction in any medium, provided the original work is properly cited.

Copyrights @ 2016 by Korean Society of Microscopy 


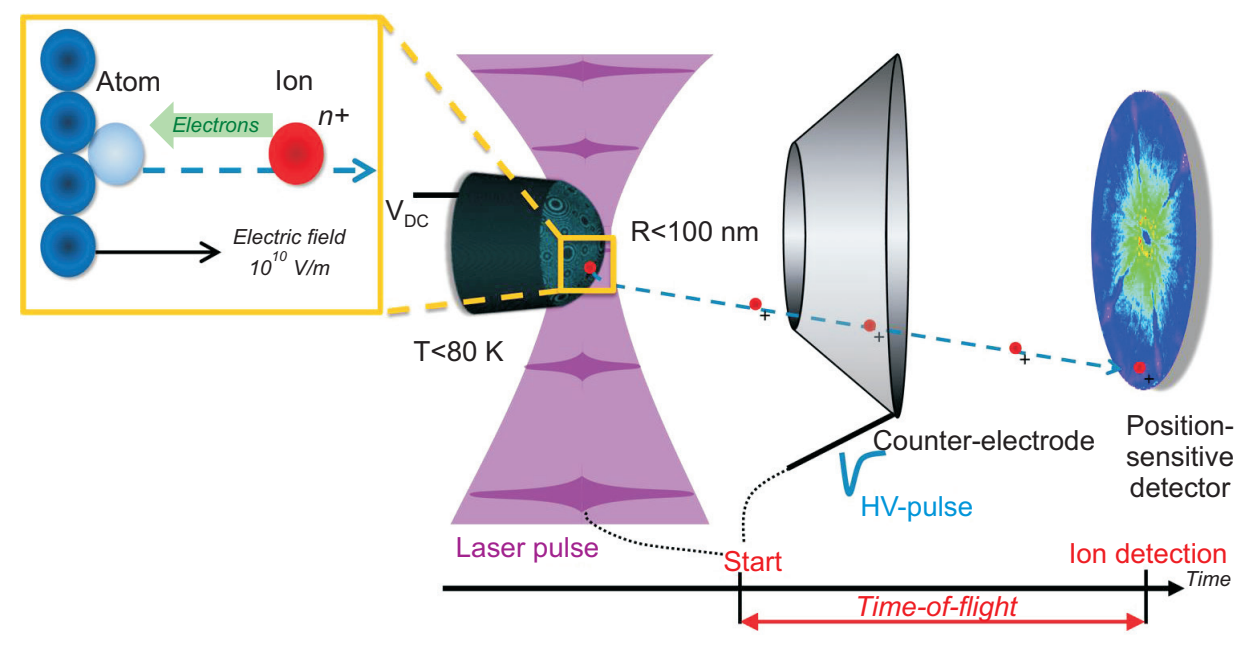

Fig. 1. Schematic view of an atom probe microscope, with the specimen subjected to a high voltage (HV) and illuminated by laser pulses of HV pulses, triggering the field evaporation of ions that fly through a counter-electrode and are collected by the position-sensitive detector, which also records their time-of-flight allowing for their elemental identification. $\mathrm{V}_{\mathrm{DC}}$, direct current high voltage; $T$, temperature.
The specimen is progressively destroyed, almost atom-byatom, and the atom probe microscope collects the timeof-flight and impact position of each ion. Processing of the data translates the time-of-flight into a mass-to-charge ratio, and the position is used to build a tomographic, atomically resolved image of the evaporated volume (Bas et al., 1995; Larson et al., 2013), represented as a point-cloud where every point is an atom that has been elementally identified and repositioned with a high degree of precision (Gault et al., 2010b).

\section{INSTRUMENTAL DESIGN}

Early designs of the technique, usually referred to as atomprobe field ion microscopes or one-dimensional (1D) atom probe (Miller, 2000; Müller et al., 1968), had a very narrow field-of-view and really only provided linear compositional measurement in the depth of the sample, within a region of interest located by field-ion microscopy (Brenner \& Goodman, 1971). APT was truly enabled by the implementation of position-sensitive, time-resolved particle detectors by Cerezo et al. (1988) followed by Blavette et al. (1993), and modern microscopes are equipped with delayline detectors (Da Costa et al., 2005; Jagutzki et al., 2002). The incorporation of micro-channel plates (MCPs) in the design of such detectors, to convert the impact of a single-ion into a cascade of up to millions of electrons, limits the efficiency approximately to the open area of the MCPs, so between $50 \% \sim 80 \%$. The MCPs are operated in saturated mode, which ensures almost no mass or atomic number sensitivity for ions in the range of $2 \sim 3 \mathrm{kV}$ up to $15 \sim 20 \mathrm{kV}$ up to several hundreds of $\mathrm{Da}$, and the loss of ions is therefore nonspecific and assumed to be random and hence not affecting the technique's capacity to precisely measure the elemental composition. In order to increase the mass resolution of the technique, limited by the energy spread of the emitted ions, reflectron-lenses were fitted onto atom probes (Bémont et al., 2003; Cerezo et al., 1998; Panayi, 2006). A reflectron acts as an electrostatic mirror: ions penetrate inside a region containing a well-defined electric field in which ions are progressively slowed down until they are returned almost $180^{\circ}$. An ion entering the reflectron with more energy travels inside the reflectron farther than an ion with less energy, which results in ions with different kinetic energies having the same timeof-flight when they are collected by the detector, which in turns increases dramatically the mass resolving power of the technique (Clifton et al., 2008).

State-of-the-art instruments are based on the design by Kelly et al. (2004), that stems from preliminary work by Nishikawa et al. (2000) to implement a micro-electrode placed near the specimen in order to locally enhance the electric field in a very confined region thereby allowing to individually address one of several specimens mounted on the same sample-holder, as well as reducing the voltage necessary to reach the critical field at which surface atoms get emitted, allowing for voltage pulsing with higher repetition rates to be used. The timing accuracy reached by modern electronics has enabled to lower the flight path, thereby increasing significantly the angular field-of-view of the technique (Deconihout et al., 2007; Kelly et al., 2004). This commercial microscope design, with much higher ease of use, has enabled significantly higher yield and higher throughput, has been one of the critical aspects to the recent breakthrough of the technique.

The other two critical aspects have been progress in the preparation of specimens using focused-ion beam techniques and the implementation of the laser-pulsing capabilities. Historically, specimens for APT were prepared by electrochemical polishing wires or thin match-stick pieces of the material of interest (Melmed, 1991), a method mostly only amenable to electroconductive materials. The 
preparation of specimens from semiconductors and oxides via a chemical polishing route was complex and not as reliable (Melmed et al., 1981; Nakamura \& Kuroda, 1978). Alternative routes using broad- or focused-ion beam milling to prepare sharp, needled-shaped specimens were investigated with some success (Larson et al., 1998; Walls et al., 1974; Waugh et al., 1984). The past decades have seen a rapid spread of scanning electron microscopes incorporating a focused-ion beam as a second source, often equipped with a gas-injection system that allows for localized chemical-vapor deposition of various metals $(\mathrm{Pt}, \mathrm{W})$ assisted by the secondary electrons emitted by the surface upon illumination by the electronor ion-beam, as well as a micromanipulator that consists in a needle that can be precisely moved inside the microscope chamber. Combining these different elements enables to liftout a small piece of the material, usually containing a specific region of interest, that can then be mounted onto a support grid or array of pre-sharpened posts, and finally shaped into one or several APT specimens (Felfer et al., 2012; Miller \& Russell, 2006; Thompson et al., 2007). FIB-based specimen preparation therefore allows to select the region that is then to be analyzed, instead of blindly hoping to find it inside the specimen, and with an enhanced field-of-view, it is then possible to perform targeted APT analysis of a specific feature (e.g., phase, grain boundary, interface).

In parallel, from the early 2000s, a strong effort started to revive the pulsed-laser atom probe. Early implementation of such instruments made use of nanosecond laser sources (Kellogg \& Tsong, 1980; Tsong et al., 1982), and, mostly due to the very strong heating of the specimen under illumination (Kellogg, 1981), were not considered not reliable enough for atom probe microanalysis, and were therefore confined to studying fundamental aspects of high-field nanoscience (Kellogg, 1982; Tsong \& Kinkus, 1984). The availability of commercial, reliable laser sources delivering pulses in the picosecond and sub-picosecond range renewed the interest in the pulsed-laser atom probe, and from 2003 Imago Scientific Instruments (Bunton et al., 2007), shortly followed by academic groups (Cerezo et al., 2007a; Gault et al., 2006), pushed the development of a new generation of instruments, partly driven by the hope of exploiting nonthermal emission (Stoian et al., 2000). After much debate within the community on the active mechanism that leads to the emission of ions (Gault et al., 2005, 2007; Vella et al., 2006, 2007), it seems that for metals the field evaporation is caused by a fast increase and quenching of the temperature of the specimen's surface subsequent to absorption of photons from the laser pulse (Vurpillot et al., 2009). This thermal pulse is usually short enough that the mass resolution is improved or at least equivalent to voltage-pulsed APT, and, although a degradation of the spatial resolution could be noticed under certain conditions (Gault et al., 2010c, 2011a; Vurpillot et al., 2009), the performance of pulsed-laser APT are usually satisfactory. It must be stressed that much of the physics of the field evaporation of semiconductors and insulators remains poorly understood and is still a matter of intense discussion in the community (Gilbert et al., 2007; Karahka et al., 2015; Kelly et al., 2014; Silaeva et al., 2013, 2014), and molecular ions are often detected and their influence on the analytical capabilities of the technique is rather difficult to measure precisely (Gault et al., 2016; Müller et al., 2011a, 2011b).

\section{DATA TREATMENT AND RECONSTRUCTION}

APT data can be separated into raw data, the direct output from the microscope, and a point cloud where every ion has been identified and allocated a position in the threedimensional (3D) reconstruction. For each ion, the timeof-flight and the corresponding two-dimensional position the impact are recorded, and the details of how the detector associates positions and time-of-flight are described in ref. (Da Costa et al., 2005; Jagutzki et al., 2002). The time-of-
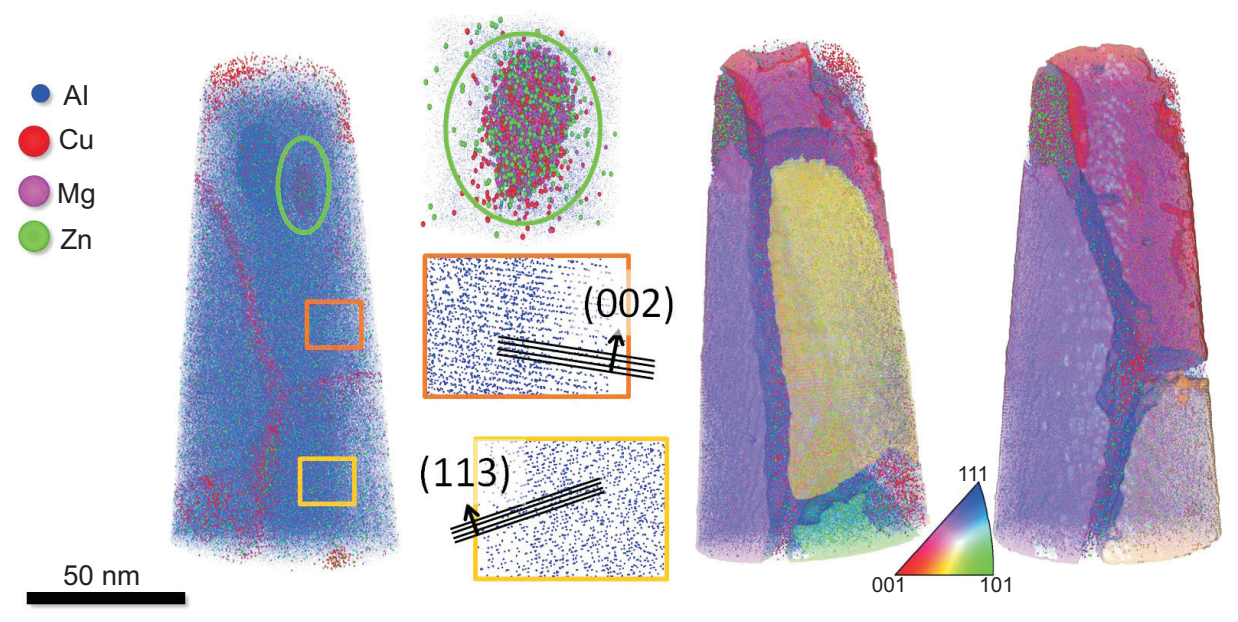

Fig. 2. Point cloud showing the elemental distribution in the analysis of a nanocrystalline Al-alloy where segregation of solutes to the grain boundaries is readily visible (for more details on the materials \& analysis, please refer to Sha et al. [2011]), with a close up on a single precipitate and different families of atomic planes. Two projections of the same volume where individual grains are highlighted by isodensity surfaces are also displayed, and coloured according to their orientation relative to the $\mathrm{z}$-axis of the tomogram. 
flight is converted into a mass-to-charge ratio (Müller et al., 1968) usually displayed in the form of a histogram, the mass spectrum, that is optimized using methods outlined by Sebastian et al. (2001). The impact position is used, assuming a simple projection law, to build a $3 \mathrm{D}$ point cloud of the analyzed volume of material (Bas et al., 1995; Gault et al., 2011b; Larson et al., 2013), as illustrated in the case of an Alalloy in Fig. 2 (Sha et al., 2011). The current reconstruction has severe drawbacks that have been discussed at length in recent review articles (Larson et al., 2013; Vurpillot et al., 2013), but they mostly relate to the complex shape of the specimen surface during the field evaporation process that is not accounted for by the current method (Gault et al., 2010a; Rolland et al., 2015).

After the point cloud has been generated, a wide variety of methods can be used to extract or to visualize features from within the point cloud, as well as quantify the local elemental composition, as summarised in Fig. 3 (Gault et al., 2013).

The point cloud can be directly interrogated. By applying a threshold on the distance between pairs of atoms of one or more specific element, it becomes possible to extract individual atomic clusters present within the data and perform quantitative analysis, as illustrated in Fig. 3B. The various flavours of cluster-finding methods were thoroughly reviewed in reference (Marquis \& Hyde, 2010). At the moment, most of those methods suffer from a lack of consistency in the definition and usage of the parameters used to define the clusters (Marceau et al., 2011). Other approaches involve dividing the point cloud into a number of blocks and then count atoms of each element and compare to a random distribution to assess possible clustering tendencies in the distribution of solutes (Moody et al., 2007, 2008). Another example the point-to-point distances can be computed, thereby allowing to access i.e. the distance between an atom and its successive shells of nearest-neighbouring (Fig. 3C) atoms which can be similarly used to investigate clustering between atoms of the same or other elemental nature (Shariq et al., 2006; Stephenson et al., 2007, 2013). From this distribution of distances, radial or pair distribution functions (De Geuser et al., 2006; Haley et al., 2009; Marquis, 2002) can also be derived, which also enable to reveal clustering tendencies.

Other commonly used are approaches to interrogate the point cloud to derive the local concentration, or its evolution, within a specific region of interest using composition profiles or ladder diagrams. In addition, isoconcentration or isodensity surfaces can be generated based on a voxelisation of the tomogram (Sha et al., 2011), and then generating a surface that encompasses areas of the data containing more than a specified threshold composition or density of one or more species. This is a useful tool to highlight regions of different composition. An example of such surfaces is also shown in Fig. 3A. Quantitative analysis based on isosurfaces can also be achieved via the so-called proximity histogram
A

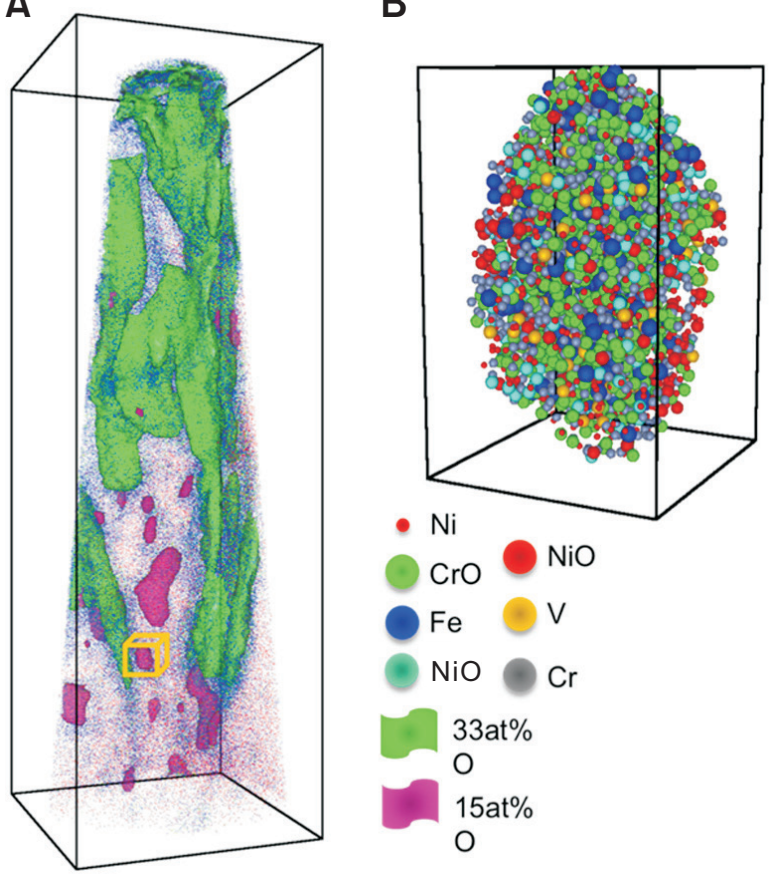

C

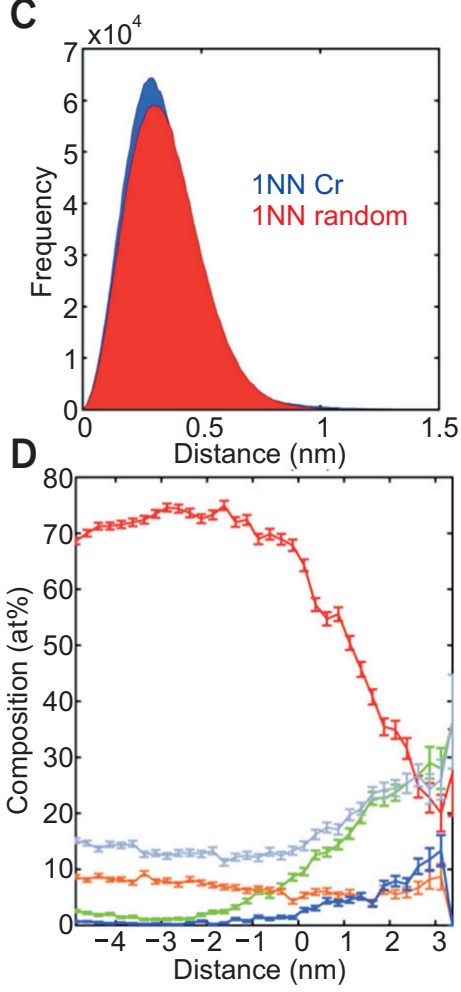

Fig. 3. Dataset of an oxidised Nickelbased alloy (corroded in hydrogenated steam at $480^{\circ} \mathrm{C}$ ) (Gault et al., 2013). (A) Point-cloud and isoconcentration surfaces highlighting the internal oxidation process coming from the surface as well as small oxide islands in the bulk of the sample. (B) Individual cluster isolated from within the data using a cluster-identification method, highlighted with the yellow cube in (A). (C) First nearest-neighbour distribution for $\mathrm{Cr}$ showing a slight clustering tendency. (D) Composition profile in the form of a proximity histogram from the isoconcentration surface within the yellow cube in (A). 
analysis (Hellman et al., 2000), which calculates a profile of concentration along the local normal to the surface, and integrates over the entire surface, and an example of such a proxigram is shown in Fig. 3D. Some issues with this approach were highlighted in a recent article (Marceau et al., 2011).

Finally, some methods have been developed to interrogate the structural integrity of the point cloud. Fourier transforms (Vurpillot et al., 2001, 2004) for instance, or real-space alternative such as the so-called 'atom vicinity' method (Boll et al., 2007) or spatial distribution maps (Geiser et al., 2007; Moody et al., 2009), which are a more or less a different representation of a split 3D radial distribution function, or the Hough transform (Yao et al., 2011) and related techniques (Araullo-Peters et al., 2015). Three main uses of these methods have so far been reported: help calibrate reconstructions (Gault et al., 2009b; Suram \& Rajan, 2013), assess the true spatial resolution of the technique (Cadel et al., 2009; Gault et al., 2009a, 2011a; Kelly et al., 2009), and finally, offer a route to rectify the data to compensate for the limited spatial resolution and reposition the atoms onto a crystalline lattice (Breen et al., 2014, 2015; Moody et al., 2011), thereby allowing for direct coupling with atomistic simulations (Moody et al., 2014).

\section{THE RISE OF APT}

APT is burgeoning, especially in comparison to some more traditional materials characterization techniques such as electron microscopy, but its rise is irresistible. When it comes to examining the evolution of a field, an in-depth bibliographical analysis can sometimes be very revealing. The graph in Fig. 4 shows the number of articles dealing with atom probe over the past five decades, with a ten-fold increase in the number of articles published yearly from 1965

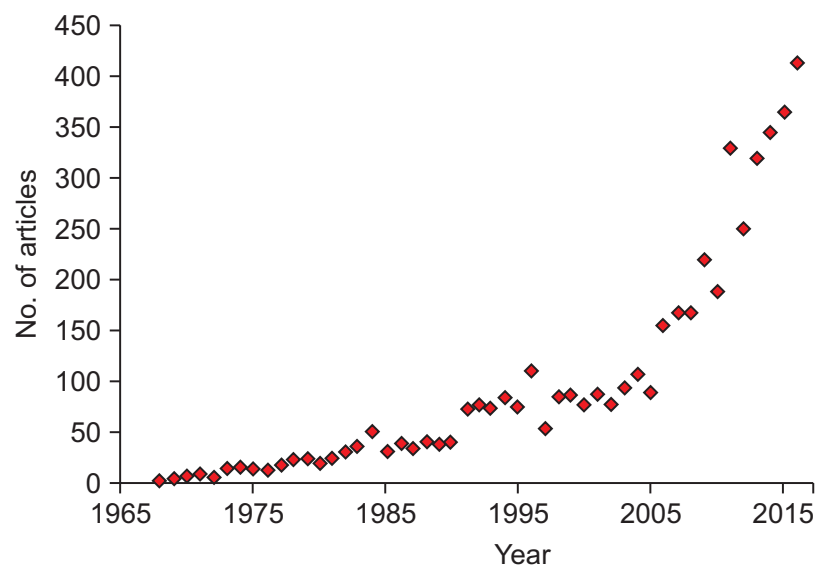

Fig. 4. Published articles with "atom probe" in the title, keyword or abstract (data from Scopus). The value for 2016 is extrapolated based on the number of articles published up to July 31, 2016. to 2015. Although there is a significant increase in the overall scientific output worldwide, the growth of the number of articles involving results from APT over 2010 2016 has been increasing at three-time the pace of the field of materials science (as indexed by Scopus). This can partly be attributed to the availability of reliable commercial instrument becoming available widely around 2004 2005, which has enabled the technique to spread beyond a community of specialists gathering every two years now at the symposium of the International Field Emission Society (now called Atom Probe Tomography \& Microscopy, recently held in Gyeongju, Korea).

In addition, based on tools made available by the Centre for Science and Technology Studies (CWTS) from the University of Leiden (http://www.vosviewer.com/), it is possibly to look at a more detailed evolution of the scientific literature: for instance Fig. 5 shows a maps of the keywords extracted from the titles of over 4,000 articles published over 1966 2016, where the size of a disc is proportional to the number of times a given word has been found, the proximity between words reflects how often they are found together, and their color reflects topical clusters that form co-appearance (Fig. 5A) and the average year where this term has most often been found

A

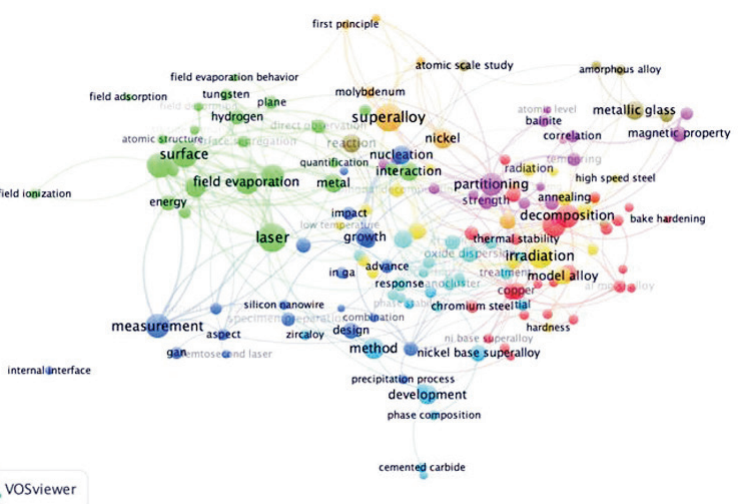

B

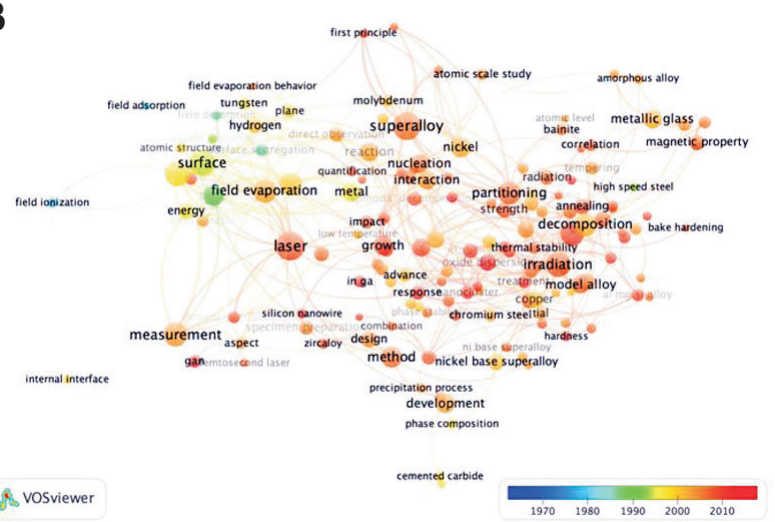

Fig. 5. Analysis of the words found in titles from over 4,000 articles published over 1966 2016 colored by topical clusters (A) or by average year (B) where a given keyword is found. 
(Fig. 5B), with blue being prior to 1980 and later than 2010. Combining these maps informs on how areas of research within the community have evolved with time, for instance studies of the more fundamental aspects of the technique in green in (Fig. 5A), appear in (Fig. 5B) to have been the focus of research earlier than some of the semiconductors-related studies (e.g., GaN, nanowires, dopant distribution), which were mostly enabled by the implementation of pulsed-laser sources on atom probe microscopes after 2004 (Bunton et al., 2006; Cerezo et al., 2007a; Gault et al., 2006). It is clear from this type of diagrams that some materials have consistently been the core of APT analysis such as Ni-based superalloys or steels, in particular for nuclear applications, but also that the technique has evolved towards a broadening of the range of materials types that are analyzed by APT, including magnetic materials (Dempsey et al., 2013), semiconductors (Kelly et al., 2007) and insulators (Gordon \& Joester, 2011; Mazumder et al., 2011; Valley et al., 2014).

A more precise map was plotted in Fig. 6, in which keywords were extracted from the titles as well as abstracts from articles published over 2010 2016. In this map, the color reflects the normalized average citations associated to these keywords. Here again, some obvious clusters of keywords form, with i.e. semiconductors and solar cells closer to the methods development, laser and field evaporation that are being intensely researched to have a better grasp on the fundamental mechanisms underpinning the field evaporation of poorconductors (Chen et al., 2011; Kelly et al., 2014; Silaeva et al., 2014). Another interesting point that arises from analyzing such diagrams is how APT is now used to complement other techniques: terms related to differential scanning calorimetry, scanning \& transmission electron microscopy, X-ray diffraction and small-angle scattering, as well as atomistic simulations, such as (kinetic) Monte Carlo, molecular dynamics or density functional theory, can all be found. This

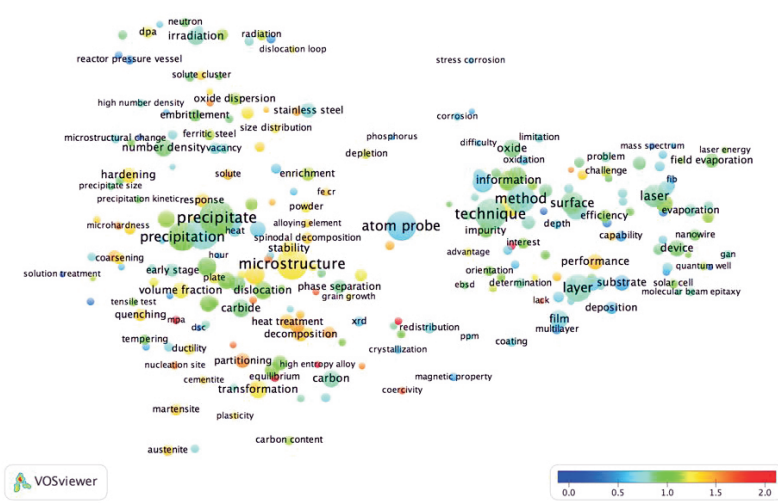

Fig. 6. Mapping of keywords extracted from titles \& abstracts of articles published over 2010 2016, colored based on their relative average citations; in red appear terms cited two or more times the average, in green around the average and in blue, below average. highlights how APT has progressively and increasingly been integrated into correlative approaches (De Geuser et al., 2014; Gault et al., 2012; Herbig et al., 2015; Krug et al., 2014; Larson et al., 2009; Mao et al., 2007), in order to best exploit its strengths.

\section{SUMMARY AND CONCLUSIONS}

To summarize, APT is a destructive analytical technique with unique capabilities to reveal the $3 \mathrm{D}$ arrangement and distribution of elements within a small volume of a solid material. The technique will turn 50 years old in 2017a special symposia at the Microscopy \& Microanalysis conference in August 2017-and it has gone through a series of revolutions, from going $1 \mathrm{D}$ to $3 \mathrm{D}$ and then from being restricted to conductors to being capable of analyzing insulators and semiconductors. Admittedly, the technique has drawbacks (i.e., small sampled volume, limited sensitivity, etc.) and suffers from a range of artifacts (Blum et al., 2016; Gault et al., 2016; Larson et al., 2013), most of which are related to a combination of many complex physical processes that can take place concomitantly or successively over the course of an atom probe experiment. The community is now working to understand some of the key issues that limit the performance and applicability of the technique to increasingly complex materials (Kelly et al., 2014; Silaeva et al., 2013).

The field of application of APT has dramatically increased, building on a vast body of work on metallic materials and alloys. Recent articles have reviewed the impact APT onto physical metallurgy or metallic alloys (Cerezo et al., 2007b;

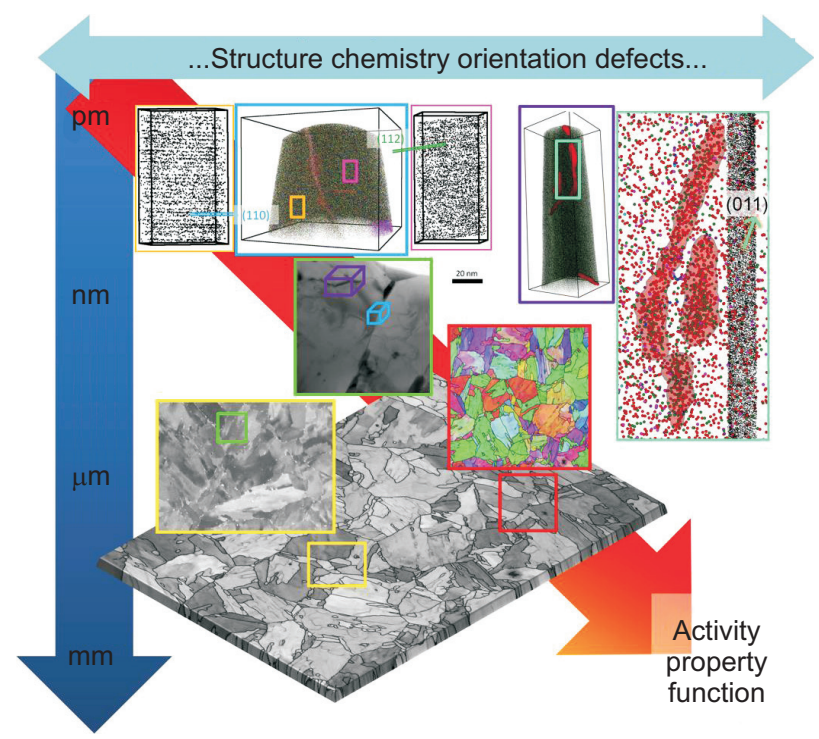

Fig. 7. Illustration of the multi-scale complexity of the microstructure of a ferritic/martensitic steel developed for power generation analysed by a range of microscopy and microanalysis techniques. 
Marquis et al., 2009a, 2009b, 2013; Seidman, 2007), as well as its capabilities for ceramics, semiconductor and devices characterization (Hono et al., 2011; Kelly et al., 2007; Larson et al., 2011a, 2011b), and I would like to refer readers to those seminal articles. Current studies are increasingly making use of a vast array of characterisation techniques, at multiple scales, with the view to correlate information from i.e. electron microscopy, optical spectroscopy or small-angle scattering (De Geuser et al., 2014; Felfer et al., 2012; Herbig et al., 2015; Kuzmina et al., 2015; Rigutti et al., 2013), and this is illustrated in Fig. 7.

Amongst new areas that are being explored, one can mention the broad front of oxidation and corrosion, where there is a strong need to establish a mechanistic understanding of complex atomic-scale phenomena that lead to the deterioration of materials (Kim et al., 2015; La Fontaine et al., 2015; Marceau et al., 2013; Meisnar et al., 2015; Schreiber et al., 2013); on the front of natural or biomaterials where the link between the nanoscale structure and properties have not often been consistently explored (Gordon \& Joester, 2011; Karlsson et al., 2014; La Fontaine et al., 2016), and, very recently geological materials (Peterman et al., 2016; Valley et al., 2014) where the local composition can be related to the history and age of the material.

The APT community has grown tremendously and will continue to do so, and the instrumental advances will help push more frontiers in materials science and technology.

\section{CONFLICT OF INTEREST}

No potential conflict of interest relevant to this article was reported.

\section{ACKNOWLEDGMENTS}

I am very grateful for the constant support and interactions from my fellow atom probers, particularly Prof. Michael Moody for keeping the door opened and being an awesome human being, Drs Tom Kelly \& David Larson for inspiration and Clam lake experiences, and Prof. Julie Cairney and her group at The University of Sydney. I want to also take this opportunity to thank the members of the group at MPIE as well as Prof. D. Raabe for pushing me out of scientific retirement and for a very warm welcome. BG is grateful for the support found in what is described ref. (Uman et al. 2016).

\section{REFERENCES}

Araullo-Peters V J, Breen A, Ceguerra A V, Gault B, Ringer S P, and Cairney J M (2015) A new systematic framework for crystallographic analysis of atom probe data. Ultramicroscopy 154, 7-14.

Bas P, Bostel A, Deconihout B, and Blavette D (1995) A general protoco for the reconstruction of 3D atom probe data. Appl. Surf. Sci. 87, 298-304.

Beavan L A, Scanlan R M, and Seidman D N (1971) The defect structure of depleted zones in irradiated tungsten. Acta Metall. 19, 13391350.

Bémont E, Bostel A, Bouet M, Da Costa G, Chambreland S, Deconihout $B$, and Hono K (2003) Effects of incidence angles of ions on the mass resolution of an energy compensated 3D atom probe. Ultramicroscopy 95, 231-238.

Blavette D, Bostel A, Sarrau J M, Deconihout B, and Menand A (1993) An atom probe for three-dimensional tomography. Nature $\mathbf{3 6 3}, 432$ 435.

Blum I, Rigutti L, Vurpillot F, Vella A, Gaillard A, and Deconihout B (2016) Dissociation dynamics of molecular ions in high DC electric field. J. Phys. Chem. A 120, 3654-3662.

Boll T, Al-Kassab T, Yuan Y, and Liu Z G (2007) Investigation of the site occupation of atoms in pure and doped $\mathrm{TiAl} / \mathrm{Ti}_{3} \mathrm{Al}$ intermetallic. Ultramicroscopy 107, 796-801.

Breen A J, Moody M P, Ceguerra A V, Gault B, Araullo-Peters V J, and Ringer S P (2015) Restoring the lattice of Si-based atom probe reconstructions for enhanced information on dopant positioning. Ultramicroscopy 159, 314-323.
Breen A J, Xie K Y, Moody M P, Gault B, Yen H W, Wong C C, Cairney J $M$, and Ringer S P (2014) Resolving the morphology of niobium carbonitride nano-precipitates in steel using atom probe tomography. Microsc. Microanal. 20, 1100-1110.

Brenner S S and Goodman S R (1971) FIM-atom probe analysis of thin nitride platelets in Fe-3 at.\% Mo. Scripta Metall. 5, 865-869.

Bunton J, Lenz D, Olson J, Thompson K, Ulfig R, Larson D, and Kelly T (2006) Instrumentation developments in atom probe tomography: applications in semiconductor research. Microsc. Microanal. 12, 1730-1731.

Bunton J H, Olson J D, Lenz D R, and Kelly T F (2007) Advances in pulsedlaser atom probe: instrument and specimen design for optimum performance. Microsc. Microanal. 13, 418-427.

Cadel E, Vurpillot F, Lardé R, Duguay S, and Deconihout B (2009) Depth resolution function of the laser assisted tomographic atom probe in the investigation of semiconductors. J. Appl. Phys. 106, 044908.

Cerezo A, Clifton P H, Gomberg A, and Smith G D W (2007a) Aspects of the performance of a femtosecond laser-pulsed 3-dimensional atom probe. Ultramicroscopy 107, 720-725.

Cerezo A, Clifton P H, Galtrey M J, Humphreys C J, Kelly T F, Larson D J, Lozano-Perez S, Marquis E A, Oliver R A, and Sha G (2007b) Atom probe tomography today. Mater. Today 10, 36-42.

Cerezo A, Godfrey T J, Sijbrandij S J, Smith G D W, and Warren P J (1998) Performance of an energy-compensated three-dimensional atom probe. Rev. Sci. Instrum. 69, 49-58. 
Cerezo A, Godfrey T J, and Smith G D W (1988) Application of a positionsensitive detector to atom probe microanalysis. Rev. Sci. Instrum. $\mathbf{5 9}$, 862-866.

Chen Y M, Ohkubo T, and Hono K (2011) Laser assisted field evaporation of oxides in atom probe analysis. Ultramicroscopy 111, 562-566.

Clifton P H, Gribb T T, Gerstl S S A, Ulfig R M, and Larson D J (2008) Performance advantages of a modern, ultra-high mass resolution atom probe. Microsc. Microanal. 14, 454-455.

Da Costa G, Vurpillot F, Bostel A, Bouet M, and Deconihout B (2005) Design of a delay-line position-sensitive detector with improved performance. Rev. Sci. Instrum. 76, 013304.

Dagan M, Hanna L R, Xu A, Roberts S G, Smith G D W, Gault B, Edmondson P D, Bagot P A, and Moody M P (2015) Imaging of radiation damage using complementary field ion microscopy and atom probe tomography. Ultramicroscopy 159, 387-394.

De Geuser F, Dorin T, Lefebvre W, Gault B, and Deschamps A (2014) Complementarity of atom probe, small angle scattering and differential scanning calorimetry for the study of precipitation in aluminium alloys. In: Materials Science Forum, Vol. 794, eds Marthinsen K, Holmedal B, and Li Y, pp. 926-932, (Trans Tech Publications, Pfaffikon).

De Geuser F, Lefebvre W, and Blavette D (2006) 3D atom probe study of solute atoms clustering during natural ageing and pre-ageing of an Al-Mg-Si alloy. Philos. Mag. Lett. 86, 227-234.

Deconihout B, Vurpillot F, Gault B, Da Costa G, Bouet M, Bostel A, Blavette D, Hideur A, Martel G, and Brunel M (2007) Toward a laser assisted wide-angle tomographic atom-probe. Surf. Interface Anal. 39, 278282.

Dempsey N M, Woodcock T G, Sepehri-Amin H, Zhang Y, Kennedy H, Givord D, Hono K, and Gutfleisch $\mathrm{O}$ (2013) High-coercivity Nd-Fe-B thick films without heavy rare earth additions. Acta Mater. 61, 49204927.

Faulkner R G and Ralph B (1972) Field-ion microscopy of the early stages of y'precipitation in a nickel-aluminium alloy. Acta Metall. 20, 703710.

Felfer P J, Alam T, Ringer S P, and Cairney J M (2012) A reproducible method for damage-free site-specific preparation of atom probe tips from interfaces. Microsc. Res. Tech. 75, 484-491.

Forbes R G (1995) Field evaporation theory: a review of basic ideas. Appl. Surf. Sci. 87, 1-11.

Gault B, Chen Y, Moody M, Ohkubo T, Hono K, and Ringer S (2011a) Influence of the wavelength on the spatial resolution of pulsed-laser atom probe. J. Appl. Phys. 110, 094901.

Gault B, Cui X Y, Moody M P, De Geuser F, Sigli C, Ringer S P, and Deschamps A (2012) Atom probe microscopy investigation of Mg site occupancy within $\delta^{\prime}$ precipitates in an Al-Mg-Li alloy. Scripta Mater. 66, 903-906.

Gault B, Haley D, De Geuser F, Moody M, Marquis E, Larson D, and Geiser B (2011b) Advances in the reconstruction of atom probe tomography data. Ultramicroscopy 111, 448-457.

Gault B, La Fontaine A, Moody M P, Ringer S P, and Marquis E A (2010a) Impact of laser pulsing on the reconstruction in an atom probe tomography. Ultramicroscopy 110, 1215-1222.

Gault B, Moody M P, De Geuser F, Haley D, Stephenson L T, and Ringer S $P(2009 a)$ Origin of the spatial resolution in atom probe microscopy. Appl. Phys. Lett. 95, 034103.

Gault B, Moody M P, De Geuser F, La Fontaine A, Stephenson L T, Haley D, and Ringer S P (2010b) Spatial resolution in atom probe tomography. Microsc. Microanal. 16, 99-110.
Gault B, Moody M P, de Geuser F, Tsafnat G, La Fontaine A, Stephenson L T, Haley D, and Ringer S P (2009b) Advances in the calibration of atom probe tomographic reconstruction. J. Appl. Phys. 105, 034913.

Gault B, Müller M, La Fontaine A, Moody M, Shariq A, Cerezo A, Ringer S, and Smith G (2010c) Influence of surface migration on the spatial resolution of pulsed laser atom probe tomography. J. Appl. Phys. 108, 044904.

Gault B, Saxey D W, Ashton M W, Sinnott S B, Chiaramonti A N, Moody M P, and Schreiber D K (2016) Behavior of molecules and molecular ions near a field emitterThis work is a partial contribution of the US Government and therefore is not subject to copyright in the United States. New J. Phys. 18, 033031.

Gault B, Scenini F, Moody M P, Huang J H, Botton G A, Mangelinck D, Descoins M, and Newman R C (2013) Atom Probe Characterization of Corroded Alloy 600. Microsc. Microanal. 19, 1020-1021.

Gault B, Vella A, Vurpillot F, Menand A, Blavette D, and Deconihout B (2007) Optical and thermal processes involved in ultrafast laser pulse interaction with a field emitter. Ultramicroscopy 107, 713-719.

Gault B, Vurpillot F, Bostel A, Menand A, and Deconihout B (2005) Estimation of the tip field enhancement on a field emitter under laser illumination. Appl. Phys. Lett. 86, 094101.

Gault B, Vurpillot F, Vella A, Gilbert M, Menand A, Blavette D, and Deconihout B (2006) Design of a femtosecond laser assisted tomographic atom probe. Rev. Sci. Instrum. 77, 043705.

Geiser B P, Kelly T F, Larson D J, Schneir J, and Roberts J P (2007) Spatial distribution maps for atom probe tomography. Microsc. Microanal. 13, $437-447$

Gilbert M, Vurpillot F, Vella A, Bernas H, and Deconihout B (2007) Some aspects of the silicon behaviour under femtosecond pulsed laser field evaporation. Ultramicroscopy 107, 767-772.

Gordon L M and Joester D (2011) Nanoscale chemical tomography of buried organic-inorganic interfaces in the chiton tooth. Nature $\mathbf{4 6 9}$, 194-197.

Haley D, Petersen T, Barton G, and Ringer S (2009) Influence of field evaporation on radial distribution functions in atom probe tomography. Philos. Mag. 89, 925-943.

Hellman O C, Vandenbroucke J A, Rusing J, Isheim D, and Seidman D $\mathrm{N}$ (2000) Analysis of three-dimensional atom-probe data by the proximity histogram. Microsc. Microanal. 6, 437-444.

Herbig M, Choi P, and Raabe D (2015) Combining structural and chemical information at the nanometer scale by correlative transmission electron microscopy and atom probe tomography. Ultramicroscopy 153, 32-39.

Hono K, Ohkubo T, Chen Y, Kodzuka M, Oh-Ishi K, Sepehri-Amin H, Li F, Kinno T, Tomiya S, and Kanitani Y (2011) Broadening the applications of the atom probe technique by ultraviolet femtosecond laser. Ultramicroscopy 111, 576-583.

Jagutzki O, Cerezo A, Czasch A, Dorner R, Hattas M, Huang M, Mergel V, Spillmann U, Ullmann-Pfleger K, and Weber T (2002) Multiple hit readout of a microchannel plate detector with a three-layer delay-line anode. IEEE Trans. Nucl. Sci. 49, 2477-2483.

Karahka M, Xia Y, and Kreuzer H J (2015) The mystery of missing species in atom probe tomography of composite materials. Appl. Phys. Lett. 107, 062105.

Karlsson J, Sundell G, Thuvander M, and Andersson M (2014) Atomically resolved tissue integration. Nano Lett. 14, 4220-4223.

Kellogg G L (1981) Determining the field emitter temperature during laser irradiation in the pulsed laser atom probe. J. Appl. Phys. 52, 53205328. 
Kellogg G L (1982) Measurement of the charge state distribution of field evaporated ions: evidence for post-ionization. Surf. Sci. 120, 319333.

Kellogg G L and Tsong T T (1980) Pulsed-laser atom-probe field-ion microscopy. J. Appl. Phys. 51, 1184-1193.

Kelly T F, Gribb T T, Olson J D, Martens R L, Shepard J D, Wiener S A, Kunicki T C, Ulfig R M, Lenz D R, and Strennen E M (2004) First data from a commercial local electrode atom probe (LEAP). Microsc. Microanal. 10, 373-383.

Kelly T F, Larson D J, Thompson K, Alvis R L, Bunton J H, Olson J D, and Gorman B P (2007) Atom probe tomography of electronic materials. Annu. Rev. Mater. Res. 37, 681-727.

Kelly T F, Vella A, Bunton J H, Houard J, Silaeva E P, Bogdanowicz J, and Vandervorst W (2014) Laser pulsing of field evaporation in atom probe tomography. Curr. Opin. Solid State Mater. Sci. 18, 81-89.

Kelly T F, Voelkl E, and Geiser B P (2009) Practical determination of spatial resolution in atom probe tomography. Microsc. Microanal. 15, 12.

Kim J H, Kim B K, Kim D I, Choi P P, Raabe D, and Yi K W (2015) The role of grain boundaries in the initial oxidation behavior of austenitic stainless steel containing alloyed $\mathrm{Cu}$ at $700^{\circ} \mathrm{C}$ for advanced thermal power plant applications. Corros. Sci. 96, 52-66.

Kingham D R (1982) The post-ionization of field evaporated ions: a theoretical explanation of multiple charge states. Surf. Sci. 116, 273301.

Krug M E, Mao Z, Seidman D N, and Dunand D C (2014) Comparison between dislocation dynamics model predictions and experiments in precipitation-strengthened Al-Li-Sc alloys. Acta Mater. 79, 382-395.

Kuzmina M, Herbig M, Ponge D, Sandlöbes S, and Raabe D (2015) Linear complexions: confined chemical and structural states at dislocations. Science 349, 1080-1083.

La Fontaine A, Yen H-W, Felfer P J, Ringer S P, and Cairney J M (2015) Atom probe study of chromium oxide spinels formed during intergranular corrosion. Scripta Mater. 99, 1-4.

La Fontaine A, Zavgorodniy A, Liu H, Zheng R, Swain M, and Cairney J (2016) Atomic-scale compositional mapping reveals Mg-rich amorphous calcium phosphate in human dental enamel. Sci. Adv. 2, e1601145.

Larson D J, Foord D T, Petford-Long A K, Anthony T C, Rozdilsky I M, Cerezo A, and Smith G W D (1998) Focused ion-beam milling for field-ion specimen preparation:: preliminary investigations. Ultramicroscopy 75, 147-159.

Larson D J, Lawrence D, Lefebvre W, Olson D, Prosa T J, Reinhard D A, Ulfig R M, Clifton P H, Bunton J H, and Lenz D (2011a) Toward atom probe tomography of microelectronic devices. J. Phys.: Conf. Ser. Vol. 326, 012030.

Larson D J, Lawrence D, Olson D, Prosa T J, Ulfig R M, Reinhard D A, Clifton P H, Kelly T F, and Lefebvre W (2011b) From the store shelf to device-level atom probe analysis: an exercise in feasibility. In: 37th International Symposium for Testing and Failure Analysis, pp. 189 197, (ISTFA 2011, San Jose).

Larson D J, Cerezo A, Juraszek J, Hono K, and Schmitz G (2009) Atomprobe tomographic studies of thin films and multilayers. MRS Bull. 34, 732-737.

Larson D J, Gault B, Geiser B P, De Geuser F, and Vurpillot F (2013) Atom probe tomography spatial reconstruction: status and directions. Curr. Opin. Solid State Mater. Sci. 17, 236-247.
Mao Z G, Sudbrack C K, Yoon K E, Martin G, and Seidman D N (2007) The mechanism of morphogenesis in a phase-separating concentrated multicomponent alloy. Nat. Mater. 6, 210-216.

Marceau R K W, Stephenson L T, Hutchinson C R, and Ringer S P (2011) Quantitative atom probe analysis of nanostructure containing clusters and precipitates with multiple length scales. Ultramicroscopy 111, 738-742.

Marceau R K W, Gutierrez-Urrutia I, Herbig M, Moore K L, Lozano-Perez S, and Raabe D (2013) Multi-scale correlative microscopy investigation of both structure and chemistry of deformation twin bundles in $\mathrm{Fe}$ Mn-C steel. Microsc. Microanal. 19, 1581-1585.

Marquis E A (2002) Microstructural evolution and strengthening mechanisms in Al-Sc and Al-Mg-Sc alloys, Ph.D dissertation, (Northwestern University, Evanston).

Marquis E A, Bachhav M, Chen Y, Dong Y, Gordon L M, and McFarland A (2013) On the current role of atom probe tomography in materials characterization and materials science. Curr. Opin. Solid State Mater. Sci. 17, 217-223.

Marquis E A and Hyde J M (2010) Applications of atom-probe tomography to the characterisation of solute behaviours. Mater. Sci. Eng. $R$ Reports 69, 37-62.

Marquis E A, Hyde J M, Saxey D W, Lozano-Perez S, de Castro V, Hudson D, Williams C A, Humphry-Baker S, and Smith G D (2009a) Nuclear reactor materials at the atomic scale. Mater. Today 12, 30-37.

Marquis E A, Miller M K, Blavette D, Ringer S P, Sudbrack C K, and Smith G D (2009b) Structural materials: understanding atomic-scale microstructures. MRS Bull. 34, 725-731.

Mazumder B, Vella A, and Déconihout B (2011) Evaporation mechanisms of $\mathrm{MgO}$ in laser assisted atom probe tomography. Ultramicroscopy 111, $571-575$

Meisnar M, Moody M, and Lozano-Perez S (2015) Atom probe tomography of stress corrosion crack tips in SUS316 stainless steels. Corros. Sci. 98, 661-671.

Melmed A J, Sakurai T, Kuk Y, and Givargizov E I (1981) Feasibility of ToF atom-probe analysis of silicon. Surf. Sci. 103, L139-L142.

Melmed A J (1991) The art and science and other aspects of making sharp tips. J. Vac. Sci. 9, 601-608.

Miller M K (2000) The development of atom probe field-ion microscopy. Mater. Charact. 44, 11-27.

Miller M K and Russell K F (2006) Atom probe specimen preparation with a dual beam FIB Miller. In: 2006 19th International Vacuum Nanoelectronics Conference, pp. 147-148, (IEEE).

Moody M P, Ceguerra A V, Breen A J, Cui X Y, Gault B, Stephenson L T, Marceau R K, Powles R C, and Ringer S P (2014) Atomically resolved tomography to directly inform simulations for structure-property relationships. Nat. Commun. 5.

Moody M P, Gault B, Stephenson L T, Haley D, and Ringer S P (2009) Qualification of the tomographic reconstruction in atom probe by advanced spatial distribution map techniques. Ultramicroscopy 109, 815-824.

Moody M P, Gault B, Stephenson L T, Marceau R K, Powles R C, Ceguerra A V, Breen A J, and Ringer S P (2011) Lattice rectification in atom probe tomography: toward true three-dimensional atomic microscopy. Microsc. Microanal. 17, 226-239.

Moody M P, Stephenson L T, Ceguerra A V, and Ringer S P (2008) Quantitative binomial distribution analyses of nanoscale like-solute atom clustering and segregation in atom probe tomography data. Microsc. Res. Tech. 71, 542-550. 
Moody M P, Stephenson L T, Liddicoat P V, and Ringer S P (2007) Contingency table techniques for three dimensional atom probe tomography. Microsc. Res. Tech. 70, 258-268.

Müller E W (1956) Resolution of the atomic structure of a metal surface by the field ion microscope. J. Appl. Phys. 27, 474-476.

Müller E W and Bahadur K (1956) Field ionization of gases at a metal surface and the resolution of the field ion microscope. Phys. Rev. 102, 624.

Müller E W, Panitz J A, and McLane S B (1968) The atom-probe field ion microscope. Rev. Sci. Instrum. 39, 83-86.

Müller M, Gault B, Smith G D W, and Grovenor C R M (2011a) Accuracy of pulsed laser atom probe tomography for compound semiconductor analysis. J. Phys.: Conf. Ser. 326, 012031.

Müller M, Saxey D W, Smith G D W, and Gault B (2011b) Some aspects of the field evaporation behaviour of GaSb. Ultramicroscopy 111, 487492.

Nakamura S and Kuroda T (1978) Atom-probe fim studies of $\beta$-SiC whiskers. Surf. Sci. 70, 452-458.

Nishikawa O, Ohtani Y, Maeda K, Watanabe M, and Tanaka K (2000) Development of the scanning atom probe and atomic level analysis. Mater. Charact. 44, 29-57.

Panayi $P$ (2006) A reflectron for use in a three-dimensional atom probe. Gt. Britain Pat. \# GB2426120A.

Peterman E M, Reddy S M, Saxey D W, Snoeyenbos D R, Rickard W D, Fougerouse D, and Kylander-Clark A R (2016) Nanogeochronology of discordant zircon measured by atom probe microscopy of $\mathrm{Pb}$ enriched dislocation loops. Sci. Adv. 2, e1601318.

Rigutti L, Vella A, Vurpillot F, Gaillard A, Sevelin-Radiguet N, Houard J, Hideur A, Martel G, Jacopin G, and Bugallo A D L (2013) Coupling atom probe tomography and photoluminescence spectroscopy: exploratory results and perspectives. Ultramicroscopy 132, 75-80.

Rolland N, Larson D J, Geiser B P, Duguay S, Vurpillot F, and Blavette D (2015) An analytical model accounting for tip shape evolution during atom probe analysis of heterogeneous materials. Ultramicroscopy 159, 195-201.

Schreiber D K, Olszta M J, Saxey D W, Kruska K, Moore K, Lozano-Perez S, and Bruemmer S M (2013) Examinations of oxidation and sulfidation of grain boundaries in alloy 600 exposed to simulated pressurized water reactor primary water. Microsc. Microanal. 19, 676-687.

Sebastian J T, Hellman O C, and Seidman D N (2001) New method for the calibration of three-dimensional atom-probe mass spectra. Rev. Sci. Instrum. 72, 2984-2988.

Seidman D N (2007) Three-dimensional atom-probe tomography: advances and applications. Annu. Rev. Mater. Res. 37, 127-158.

Sha G, Yao L, Liao X, Ringer S P, Duan Z C, and Langdon T G (2011) Segregation of solute elements at grain boundaries in an ultrafine grained Al-Zn-Mg-Cu alloy. Ultramicroscopy 111, 500-505.

Shariq A, Al-Kassab T, Kirchheim R, Safarik D J, and Schwarz R B (2006) Exploring the next neighbourhood relationship in metallic glasses utilizing the atom probe tomography. In: 2006 19th International Vacuum Nanoelectronics Conference, pp. 19-20, (IEEE).

Silaeva E P, Arnoldi L, Karahka M L, Deconihout B, Menand A, Kreuzer H J, and Vella A (2014) Do dielectric nanostructures turn metallic in highelectric dc fields? Nano Lett. 14, 6066-6072.

Silaeva E P, Karahka M, and Kreuzer H J (2013) Atom probe tomography and field evaporation of insulators and semiconductors: theoretical issues. Curr. Opin. Solid State Mater. Sci. 17, 211-216.
Stephenson L T, Moody M P, Gault B, and Ringer S P (2013) Nearest neighbour diagnostic statistics on the accuracy of APT solute cluster characterisation. Philos. Mag. 93, 975-989.

Stephenson L T, Moody M P, Liddicoat P V, and Ringer S P (2007) New techniques for the analysis of fine-scaled clustering phenomena within atom probe tomography (APT) data. Microsc. Microanal. 13, 448-463.

Stoian R, Ashkenasi D, Rosenfeld A, and Campbell E E B (2000) Coulomb explosion in ultrashort pulsed laser ablation of $\mathrm{Al}_{2} \mathrm{O}_{3}$. Phys. Rev. $\mathrm{B} \mathbf{6 2}$, 13167

Suram S K and Rajan K (2013) Calibration of reconstruction parameters in atom probe tomography using a single crystallographic orientation. Ultramicroscopy 132, 136-142.

Thompson K, Lawrence D, Larson D J, Olson J D, Kelly T F, and Gorman B (2007) In situ site-specific specimen preparation for atom probe tomography. Ultramicroscopy 107, 131-139.

Tsong T T and Kinkus T J (1984) Energy distributions of pulsed-laser fielddesorbed gaseous ions and field-evaporated metal ions: a direct time-of-flight measurement. Phys. Rev. B 29, 529.

Tsong T T, McLane S B, and Kinkus T J (1982) Pulsed-laser time-of-flight atom-probe field ion microscope. Rev. Sci. Instrum. 53, 1442-1448.

Uman E, Colonna-Dashwood M, Colonna-Dashwood L, Perger M, Klatt C, Leighton S, Miller B, Butler K T, Melot B C, Speirs R W, and Hendon $\mathrm{C} \mathrm{H}$ (2016) The effect of bean origin and temperature on grinding roasted coffee. Sci. Rep. 6, 24483.

Valley J W, Cavosie A J, Ushikubo T, Reinhard D A, Lawrence D F, Larson D J, Clifton P H, Kelly T F, Wilde S A, and Moser D E (2014) Hadean age for a post-magma-ocean zircon confirmed by atom-probe tomography. Nat. Geosci. 7, 219-223.

Vella A, Deconihout B, Marrucci L, and Santamato E (2007) Femtosecond field ion emission by surface optical rectification. Phys. Rev. Lett. 99, 046103.

Vella A, Vurpillot F, Gault B, Menand A, and Deconihout B (2006) Evidence of field evaporation assisted by nonlinear optical rectification induced by ultrafast laser. Phys. Rev. B 73, 165416.

Vurpillot F, Da Costa G, Menand A, and Blavette D (2001) Structural analyses in three-dimensional atom probe: a Fourier transform approach. J. Microsc. 203, 295-302.

Vurpillot F, De Geuser F, Da Costa G, and Blavette D (2004) Application of Fourier transform and autocorrelation to cluster identification in the three-dimensional atom probe. J. Microsc. 216, 234-240.

Vurpillot F, Gault B, Geiser B P, and Larson D J (2013) Reconstructing atom probe data: a review. Ultramicroscopy 132, 19-30.

Vurpillot F, Houard J, Vella A, and Deconihout B (2009) Thermal response of a field emitter subjected to ultra-fast laser illumination. J. Phys. D-Applied Phys. 42, 125502.

Walls J M, Southworth H N, and Rushton G J (1974) The preparation of field electron/field-ion emitters by ion etching. Vacuum 24, 475-479.

Waugh A R, Payne S, Worrall G M, and Smith G D W (1984) In situ ion milling of field ion specimens using a liquid metal ion source. J. Phys. Colloq. 45, C9-207-C9-209.

Wilde J, Cerezo A, and Smith G D W (2000) Three-dimensional atomicscale mapping of a cottrell atmosphere around a dislocation in iron. Scripta Mater. 43, 39-48.

Yao L, Moody M P, Cairney J M, Haley D, Ceguerra A V, Zhu C, and Ringer S P (2011) Crystallographic structural analysis in atom probe microscopy via 3D Hough transformation. Ultramicroscopy 111, 458463. 